\title{
An unusual homing behavior found in the Sichuan Partridge during the early brooding period
}

Yiqiang $\mathrm{Fu}^{1,2^{*}}$, Shufang Wang ${ }^{1}$, Benping Chen ${ }^{3}$, Simon Dowell ${ }^{4}$ and Zhengwang Zhang ${ }^{5^{*}}$

\begin{abstract}
In this study, we report an unusual homing behavior of the Sichuan Partridge (Arborophila rufipectus) at the Laojunshan National Nature Reserve, Sichuan Province, China. Hen Sichuan Partridges led the chicks back to the nests where they hatched in the evening and roosted there over night. This behavior lasted $6.7 \pm 4.3$ nights (range $=1-15 ; n=13$ ) after the chicks hatched. At this stage, the hens became very vigilant to predators and human disturbance. If disturbed, they often abandoned the nests immediately and no longer returned thereafter. The ambient temperature at night during the early brooding period of Sichuan Partridge at our study site was $\sim 12.4^{\circ} \mathrm{C}$. Our findings suggest that hen Sichuan Partridges may make trade-offs between nest predation risks versus the thermoregulatory needs of their young.
\end{abstract}

Keywords: Arborophila rufipectus, Early brooding period, Homing behavior, Predation risk, Thermoregulation

\section{Correspondence}

In the breeding season, birds build nests to protect their eggs and young from predators and adverse weather conditions (Zheng 2012; Deeming and Reynolds 2015). However, most birds rarely return to their nests after fledging as this could make them more vulnerable to predators and increase exposure to nest ectoparasites (Scholer 2015). There are only a few reports of reuse of old nests by recently fledged young, such as the Ferruginous Hawk (Buteo regalis) in South Dakota, in which the young returned to the nests to obtain food from the adults and to roost for another 2 weeks after fledging (Blair and Schitoskey 1982). Galliformes are a group of precocial species that chicks leave the nest soon after hatching and move around for foraging following the hen (Zheng

\footnotetext{
*Correspondence: fyq512@126.com; zzw@bnu.edu.cn

${ }^{1}$ College of Life Sciences, Sichuan Normal University, Chengdu 610101,

Sichuan, China

${ }^{5}$ Ministry of Education Key Laboratory for Biodiversity Science

and Ecological Engineering, College of Life Sciences, Beijing Normal University, Beijing 100875, China

Full list of author information is available at the end of the article
}

2015). There are not any reports in wild Galliformes that the chicks return to their nests during the brooding period (McGowan 1994).

The Sichuan Partridge (Arborophila rufipectus) is a globally endangered Galliforme species native to the mountains of southwest China. It builds a domed, and partially enclosed nest with a $6-8 \mathrm{~cm} \times 8-10 \mathrm{~cm}$ entrance (Fu et al. 2017). During the breeding season of 2011, we first noted that hen Sichuan Partridges led their newly hatched chicks back to the nests where they were born, and then roosted in the nests all together over night. We continued to observe this behavior in the field from 2011 to 2019. The aims of this study were to describe this unusual homing behavior and preliminarily analyze its ecological significance.

The study was carried out at the Laojunshan National Nature Reserve $\left(28^{\circ} 39^{\prime} 36^{\prime \prime}-28^{\circ} 43^{\prime} 38^{\prime \prime} \mathrm{N}, 1^{\circ} 03^{\circ} 57^{\prime} 36^{\prime \prime}\right.$ $104^{\circ} 04^{\prime} 12^{\prime \prime} \mathrm{E}$; altitude $900-2009 \mathrm{~m}$ ) in southwest China. The climate is temperate with high precipitation ( $>1500 \mathrm{~mm}$ per year) and relative humidity $(>85 \%)$. The average annual temperature is about $12.0-14.7{ }^{\circ} \mathrm{C}$. The vegetation is characterized by evergreen broadleaf forest, 
mainly including Castanopsis spp., Schima spp., Camellia spp., Eurya spp., and Rhododendron spp. The reserve has the world's largest wild population of the Sichuan Partridge, about 300-400 individuals (Fu and Chen 2017).

The nests were located through systematic searches during the breeding season. We monitored breeding behavior of the partridge using Tinytag Plus 2 temperature data loggers (TDL) (TGP-4520, Gemini Data Loggers, UK) and infrared cameras (IC) (Ltl 6210, Acorn, $\mathrm{CN}$ ). The data logger had two external probes, which allowed us to record both internal nest and corresponding ambient temperatures ( $\mathrm{Fu}$ et al. 2012). The temperature difference was taken as an indicator of adult presence and absence from the nest (Manlove and Hepp 2000; Greeney 2009). The infrared cameras placed at or around the nests were used to monitor activities of

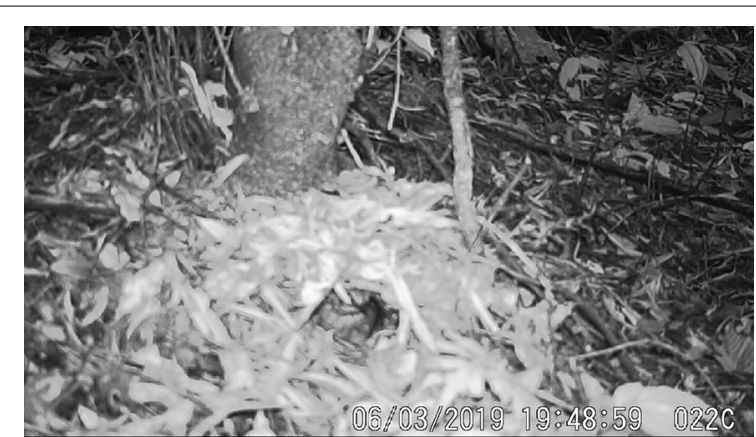

Fig. 1 The video screenshot showing that a hen Sichuan Partridge and its brood were roosting in their nest at night (data from Nest 201909)
Sichuan Partridges and their potential predators. Data are presented as mean \pm SD.

In total, 148 Sichuan Partridge nests (including 24 old nests built in the last breeding season) were found from 2011 to 2019. We monitored 60 of them with IC and (or) TDL. A total of 15 successfully hatched Sichuan Partridge nests were monitored during the nine breeding seasons.

Female Sichuan Partridges incubated alone. The incubation period was about 29 days. The chicks left nests for the first time usually in the morning or at noon 1 day after hatching. When the time arrived, the cock came to the nest and served as a guard. The hen walked out of the nest first, and then the chicks followed one by one. In the evening, the hen led the chicks back to the nest, roosting communally over night (Fig. 1), while the cock roosted alone on the tree near the nest (usually $<100 \mathrm{~m}$ ). Such homing behavior back to the nest was often repeated for multiple nights (Fig. 2). The corresponding ambient temperature at night during the early brooding period of Sichuan Partridge was $12.4 \pm 1.7^{\circ} \mathrm{C}$ ( $n=7$ nests). The patterns of incubation-hatch-homing by the Sichuan Partridge are shown in Fig. 2.

Of 15 successful nests that were monitored, the homing behavior has been observed in 13 nests (Table 1). For all the 13 nests combined, the hens and their chicks returned to their nests at 18:49 p.m. $\pm 40 \mathrm{~min}$, and left at 07:00 a.m. $\pm 36 \mathrm{~min}$. The mean homing times after hatching were $6.7 \pm 4.3$ nights (range $=1-15 ; n=13$ ). At this stage, the hens became very sensitive to the security of nest sites. If disturbed, whether by predators or human beings, they often abandoned the nests immediately and no longer returned thereafter.

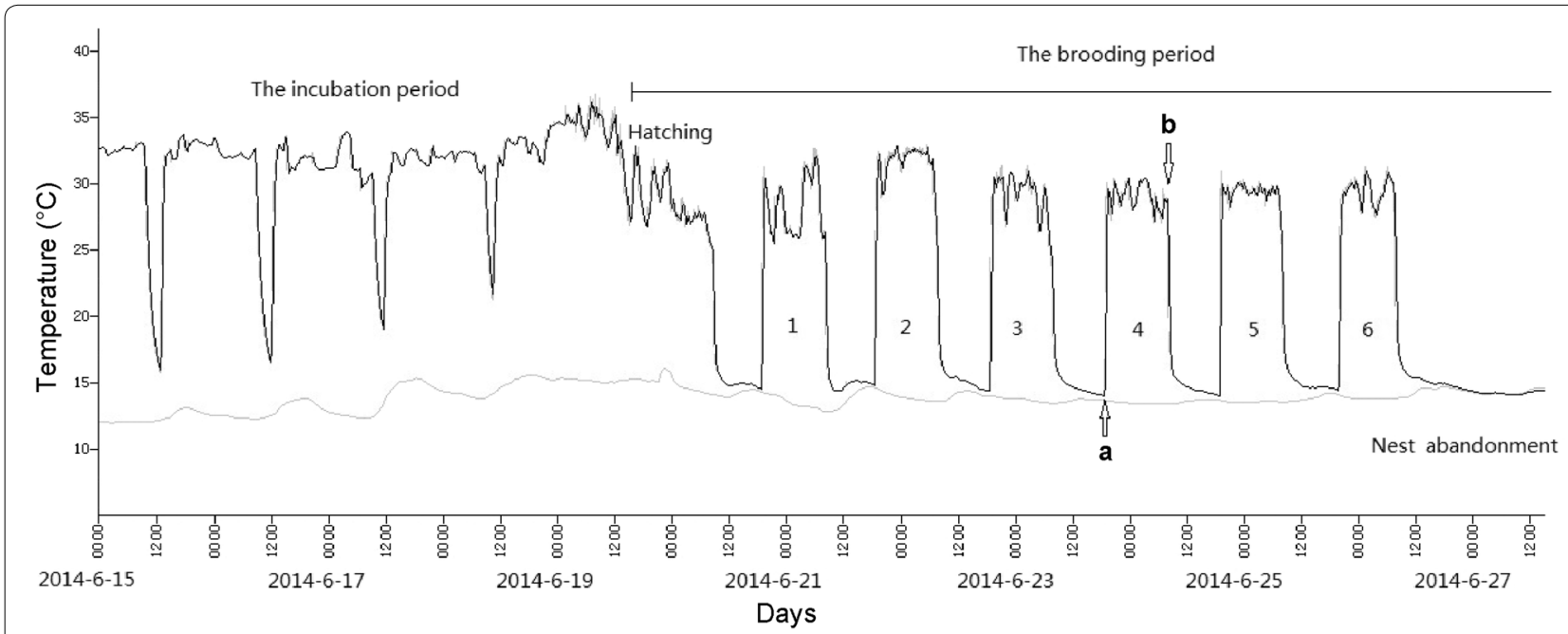

Fig. 2 The patterns of incubation-hatch-homing by a hen Sichuan Partridge at the Laojunshan Nature Reserve, Sichuan Province, China (data from Nest 201418). Black lines represent internal nest temperature, while gray lines represent corresponding ambient temperature. The numbers indicate that the hen Sichuan Partridge led the young back to the nest for six consecutive nights. The arrows indicate return (a) and departure (b) time 
Table 1 Summary of homing behavior of the Sichuan Partridge during the early brooding period at the Laojunshan National Nature Reserve, Sichuan Province, China

\begin{tabular}{llllr}
\hline Nest code & Monitoring method & No. of eggs hatched & Time for the 1st departure & $\begin{array}{c}\text { No. of homing } \\
\text { nights } \\
\text { after hatching }\end{array}$ \\
\hline 201405 & & & 0 \\
201408 & IC & 6 & 0840 & 0 \\
201401 & IC + TDL & 5 & 1010 & 1 \\
201607 & IC & 2 & 1031 & 1 \\
201315 & IC & 4 & 1005 & 3 \\
201417 & IC & 4 & 0930 & 3 \\
201106 & IC+TDL & 5 & 0855 & 5 \\
201107 & TDL & 5 & 0640 & 6 \\
201418 & IC + TDL & 3 & 1101 & 6 \\
201515 & TDL & 5 & 0835 & 7 \\
201612 & IC + TDL & 5 & 0800 & 7 \\
201409 & IC & 5 & 0713 & 10 \\
201904 & IC + TDL & 3 & 0820 & 11 \\
201905 & IC & 6 & 1118 & 12 \\
201909 & IC & 5 & 1425 & 15 \\
\hline
\end{tabular}

IC infrared camera, TDL temperature data logger

To our knowledge, this is the first report of homing behavior after hatching in any species of Galliformes in the wild. An explanation for the unusual homing behavior is compensating for the underdevelopment of thermoregulation in the chicks. In most species of Galliformes, the recently hatched chicks lack full thermoregulatory capacity (Zheng 2015). The chicks cannot maintain their own body temperature and are periodically brooded by the hen to prevent them becoming chilled. The Sichuan Partridge has an unusual incubation pattern with low nest attentiveness of $\sim 81.2 \%$ over the incubation period, and long exposures of $\sim 4.2 \mathrm{~h}$ below the physiological zero temperature of $26{ }^{\circ} \mathrm{C}$ for developing embryos for each daily recess (Fu et al. 2017). This may lead to worse development of thermoregulation in the early stage of their life of the Sichuan Partridge than other birds. The ambient temperature at night was low $\left(\sim 12.4{ }^{\circ} \mathrm{C}\right)$ during the early brooding period of the Sichuan Partridge at our study site. Therefore, hen partridges and their chicks may choose to roost communally in the domed nests with good insulation during the chilly nights, which can effectively reduce energy costs that may be critical for the development of thermoregulation in chicks.

Reducing predation risk of the broods is another explanation for the unusual homing behavior. Predation was the main cause of breeding failure of the Sichuan Partridge (Fu and Chen 2017). The partridge prefers to nest near to the trails that are frequently used by pedestrians (Fu et al. 2017). As predators may avoid areas where human activity is high, leading to spatial refuges from predation (Muhly et al. 2011), it is possible that hen partridges lead the chicks back to their nests when they perceive the risk of nest predation to be low. Besides, the main predators of the partridge are some nocturnal mammals with sensitive senses of smell, such as Prionodon pardicolor and Mustela sibirica (Fu and Chen 2017). It is also possible that the domed-shape nests of the species actually shield the chicks and might reduce their scent releasing into the air around them, thus protecting them somewhat from predators.

The homing times of Sichuan Partridge varied greatly, and the longest homing record was 15 nights (i.e., Nest 201909) (Table 1). Five cases of nest abandonment in advance (compared with Nest 201909) were caused by predators (Nests 201515, 201607, and 201905) and human disturbance (Nests 201405 and 201408), respectively. In the remaining nine cases, the reasons why they abandoned their nests were not clear. Considering that the species faces great nest predation pressure during the breeding period (Fu and Chen 2017), and the recently hatched young moves mainly around the nests not far away, we speculate that the predation risk around the nests might affect "decision-making" (homing or abandonment) of the hen Sichuan Partridges.

Scholer (2015) reported a case of post-fledging use of an old nest by an adult House Wren (Troglodytes aedon) and its brood for two consecutive nights when the temperature dropped below freezing to -2 and $-3{ }^{\circ} \mathrm{C}$, 
respectively. Preble (1961) also reported a similar incident of the Wren. As there are only two independent cases, it is difficult to assess whether this behavior is a stable survival strategy in the House Wren. However, most of the hen Sichuan Partridges in our study exhibited same homing behavior, which may represent an adaptive breeding strategy to cope with high predation pressure and low ambient temperature within their breeding habitats to increase the fitness of offspring.

In conclusion, our findings suggest that hen Sichuan Partridges may make trade-offs between the thermoregulatory needs of young versus the predation risks of the broods, which also provides evidence for flexibility in parental care behavior. Future research is needed to assess the impacts of nest ectoparasites on this unusual homing behavior. In this study, we did not track the chicks' fate due to the lack of effective individual identification and tracking technology. Further work is also needed to determine where the family groups roosted after they abandoned the nests, and what impact will these abandonments have on the survival of the young.

\section{Acknowledgements}

We thank Laojunshan Nature Reserve for allowing us to conduct this study. We thank Ming Xiang, Wencai Chen, Hongbin Li, Chiping Kong, Yongheng Wu and Bo Dai for assistance with the fieldwork. We also thank The North of England Zoological Society (Chester Zoo) for providing some of equipment and facilities for this research through their financial support for the Laojunshan Nature Reserve.

\section{Authors' contributions}

YF and ZZ conceived the study; YF and BC collected the Data; SW and SD analyzed the data; all authors contributed to manuscript preparation. All authors read and approved the final manuscript.

\section{Funding}

This work was supported by the National Natural Science Foundation of China (31872961 and 31272330), the biodiversity survey and assessment project of the Ministry of Ecology and Environment of China (2019HB2096001006), and the National Forestry and Grassland Administration of China.

\section{Availability of data and materials}

The datasets used during the current study are available from the corresponding authors on reasonable request.

\section{Ethics approval and consent to participate}

Our study was carried out in agreement with the Law of the People's Republic of China on the Protection of Wildlife and was approved by the Laojunshan National Nature Reserve Administration.

\section{Consent for publication}

Not applicable.

\section{Competing interests}

The authors declare that they have no conflict of interests.

\section{Author details}

${ }^{1}$ College of Life Sciences, Sichuan Normal University, Chengdu 610101, Sichuan, China. ${ }^{2}$ College of Life Sciences, Leshan Normal University, Leshan 614004, Sichuan, China. ${ }^{3}$ Laojunshan National Nature Reserve Administration, Pingshan 645350, Sichuan, China. ${ }^{4}$ North of England Zoological Society, Chester Zoo, Upton by Chester, Chester CH2 1LH, UK. ${ }^{5}$ Ministry of Education Key Laboratory for Biodiversity Science and Ecological Engineering, College of Life Sciences, Beijing Normal University, Beijing 100875, China.

Received: 12 August 2020 Accepted: 2 November 2020

Published online: 04 December 2020

\section{References}

Blair CL, Schitoskey F. Breeding biology and diet of the Ferruginous Hawk in South Dakota. Wilson Bull. 1982;94:46-54.

Deeming DC, Reynolds SJ. Nests, eggs, and incubation: new ideas about avian reproduction. Oxford: Oxford University Press; 2015.

Fu YQ, Chen BP. A report on the scientific investigation of Sichuan Partridge at the Laojunshan National Nature Reserve, Sichuan, China. Beijing: China Agriculture Press; 2017.

Fu YQ, Dowell SD, Zhang ZW. The application of temperature data loggers for remotely monitoring the nests of Emei Shan Liocichla (Liocichla omeiensis). Zool Sci. 2012;29:373-6.

Fu YQ, Dai B, Wen LY, Chen BP, Dowell S, Zhang ZW. Unusual incubation behavior and embryonic tolerance of hypothermia in the Sichuan Partridge (Arborophila rufipectus). J Ornithol. 2017;158:707-15.

Greeney HF. Unusual incubation rhythms of the Spotted Barbtail (Premnoplex brunnescens). J Ornithol. 2009;150:529-35.

Manlove CA, Hepp GR. Patterns of nest attendance in female wood ducks. Condor. 2000;102:286-91

McGowan PJK. Family Phasianidae (Pheasants and Partridges). In: Del Hoyo J, Elliott A, Sargatal J, editors. Handbook of the birds of the world. Volume 2: New world vultures to guineafowl. Barcelona: Lynx Edicions; 1994.

Muhly TB, Semeniuk C, Massolo A, Hickman L, Musiani M. Human activity helps prey win the predator-prey space race. PLoS ONE. 2011;6:e17050.

Preble CS. Unusual behavior of House Wren. Auk. 1961;78:442.

Scholer MN. Unusual behavior in parental care by a House Wren (Troglodytes aedon): post fledging use of an old nest during cold nights. Wilson J Ornithol. 2015;127:545-7.

Zheng GM. Ornithology. 2nd ed. Beijing: Beijing Normal University Publishing Group; 2012

Zheng GM. Pheasants in China. Beijing: Higher Education Press; 2015.

Ready to submit your research? Choose BMC and benefit from:

- fast, convenient online submission

- thorough peer review by experienced researchers in your field

- rapid publication on acceptance

- support for research data, including large and complex data types

- gold Open Access which fosters wider collaboration and increased citations

- maximum visibility for your research: over 100M website views per year

At BMC, research is always in progress.

Learn more biomedcentral.com/submissions 